\title{
Depressing news from Paris
}

\section{Paris}

TiII razzmatazz of last week's international conference on acquired immune deficiency syndrome (AIDS) in Paris was tempered by gloomy facts and figures. Unless some effective form of therapy is found. 179, (0)( ) people in the United States will dic of AIDS in the next five years; no doubts remain about the heterosexual transmission of the AIDS virus; at least half the members of several groups of intravenous drug users are now infected; the virus evolves as rapidly as the influenza virus; and it already has an alarming hold in some cities in central Africa.

There are still doubts about the validity of some of the African statistics, but those. from Kinshasa, capital of Zaire, are copious and reliable. Of a group of prostitutes, 27 per cent have been infected by the virus as have 6.5 per cent of all the patients in hospital. In Rwanda, the equivalent fig-

\section{Japan's islands coming home}

Tokyo

Fok years, the Japanese government has been doggedly trying to get the Soviet Union to return four small islands off the coast of Hokkaido seized in the closing days of the Second World War. Now a new survey shows that some of the islands will return quite soon - geologically speaking, that is.

The islands of Etorofu, Kunashiri, Shikotan and the Habomai group - the "northern territories" — were home to 16,000 Japanese before the Soviet invasion took their troops to an island within $5 \mathrm{~km}$ of the shores of Hokkaido in 1945. The continuing occupation is an endless source of friction between the two countries and has prevented Japan from concluding a post-war peace treaty with the Soviet Union, with all the trade benefits that might bring. But it seems the islands are creeping home at the rate of some 2 metres every 80 years.

The figures come from a resurvey of Hokkaido by the mapping division of the Geographical Survey Institute of the Ministry of Construction. A laser range-finder has revealed crustal movement that has occurred since an earlier triangulation survey carried out between 1908 and 1916 . Throughout most of Hokkaido, net movement has been of the order of only a few centimetres or tens of centimetres. The two closest islands, the Habomais and Shikotan, are moving very much faster. If things continue as they are, they should collide with the mainland in about one million years. David Swinbanks ures are 88 per cent and 18 per cent, with 28 per cent recorded in pregnancy. With similar figures from other countries that border on Zaire, it is clear the virus is very well established and will continue to spread from mother to child and, most importantly, by heterosexual intercourse. That accounts for the approximately equal distribution of infection between the sexes in central Africa, whereas in developed countries male homosexuals still account for about 70 per cent of cases.

In western Africa the situation is less clear and, in many ways, more interesting. There is little, if any, evidence of the presence of HTLV-III/LAV, the standard AIDS virus, but increasing evidence of the distantly related HTLV-IV and LA.V-2 viruses. It remains uncertain whether these are two names for the same virus. HTLV-IV was identified in Senegalese prostitutes whose health seems unaffected by the virus. As many as half the prostitutes in one unidentified (for political reasons) country in the region have been infected with HTLV-IV, with 38, 7 and 0 per cent in three nearby countries.

So far, not a single case of AIDS has been recorded in an HTLV-IV infected person, according to Max Essex of Harvard University. On the other hand LAV - 2 has now been isolated by the Pasteur Institute team led by Luc Montagnier from 8 AIDS or pre-AIDS patients from Guinea Bissau, Senegal and Cape Verde Islands, but its prevalence in prostitutes. or in general, is not yet known. There seems to be little prospect of an immediate exchange of material between Essex and Montagnier or, therefore, of establishing the precise relationship of the two viruses.

Hope remains that once the west African and monkey viruses have all been molecularly cloned and compared with HTLV-III/LAV, there will be a clear indication of which DNA sequences are responsible for pathogenicity and might form the best vaccines. Meanwhile, there is steady progress towards trials, perhaps later this year, of whether chimpanzees immunized with vaccinia virus enginecred to contain the envelope gene of HTLVIII/LAV will be protected against infection with the virus

There are, however, distinctly mixed views on the likely success of such a trial without (or even with) refinement of the envelope gene. Furthermore, there is cmerging evidence of the rapid evolution of the virus within individuals. Thus Beatrice Hahn of the University of Alabama reported that consecutive isolates of the virus from individual patients had distinctive genetic maps, and comparable differences between the virus from infected blood donors and their recipients were described by A. Srinivasan of the Centers for Disease Control in Atlanta. Probably both the direct evolution of the virus under pressure to escape the immune system and the emergence of different viruses from a mixed infecting population are involved. The chances of effective vaccination against such a moving target may be slim, as in the case of influenza virus.

For want of anything better as an advance in AIDS therapy, attention (certainly press attention) focused on the partial reconstitution of immune function in one AIDS patient given a bone marrow transplant from his healthy identical twin along with transfers of peripheral lymphocytes both before and after the transplant. But two other identical twins did not respond to the same form of treatment. Anthony Fauci, of the National Institutes of Health, intends to pursue such treatment, assessing the value of transplantation from matched siblings, the frequency of lymphocyte transfers and the value of simultaneous therapy with antivirals.

Little progress with antivirals was reported, although the first results of a double-blind placebo trial of azidothymidine are due this summer. Samuel Broder. of the National Cancer Institute in Maryland, who is persisting with the trial in the face of considerable pressure from some quarters simply to give the drug to all patients, is quietly optimistic about the outcome, particularly as the drug gains access at potentially therapeutic levels to the brain where it may reverse the loss of cognitive functions caused by the virus. Burroughs Wellcome, which makes azidothymidine, has exhausted the world supply of thymidine, from which it is made, but has plans to overcome this problem if the drug is shown to be valuable.

Without effective therapy, progression from infection to disease is not inevitable. but the cumulative incidence of AIDS in some well-studied cohorts of homosexuals is now around 30 per cent and showing no signs of decreasing with time. Moreover. Bob Redfield, of the Walter Reed Army Institute of Research in Washington. reported that 90 per cent of a series of patients who could be classified as belonging to one of 5 stages that precede full-blown AIDS progressed by at least one stage within $18-36$ months.

Without an effective vaccine, the only means of prevention is to avoid intimate sexual contact with infected people, and to avoid their blood or blood products. There are clear signs that some homosexual communities have effectively taken this advice to heart. But it is less certain that drug users are doing so. In the worst reported case. 76 per cent of a group of Italian drug takers are now infected, compared with 6 per cent in 1980. In some groups fewer than 10 per cent are yet infected, but the reason for these differences is still unclear. Peter Newmark 